\title{
Force Analysis of the Support Belt and Pregnant Woman for Relieving the Pregnancy-related Waist Pain *
}

\author{
Xue-lian Kang, Bo-An Ying*, Xin Zhang, Jing Qi, Long Wu \\ Apparel \& Art Design College, Xi'an Polytechnic University, Xi'an 710048, China
}

\begin{abstract}
Researching the waist support belt becomes more important. It's said that the waist support belt can help pregnant women to relieve pregnancy-related pain, but the function of support belt couldn't be unanimously identified by studies or clinical trials' confirm at present. In this paper, the force analysis model is established, aiming to detect the role of the waist support belt. Aiming at the dressing effect is not prominent, when pregnant women just wear the waist support belt. In the paper, analyzing the pain causes of the pregnant women's waist by the theory of mechanics is the basis of research. Through force analysis, it is effective to know how the support belt plays the role. Then, data by pressure test is used to understand the effect, if the support belt can relieve the waist pain of pregnant women. The result is used to verify the results of force analysis. And the data of pressure can explain its functionality. It provides a evaluation method of waist support belt through force analysis and pressure test.
\end{abstract}

Keywords: Force Analysis; The Support Belt; Relieve the Pregnancy-related Waist Pain; Pressure Test

\section{Introduction}

At present, the pregnancy-related waist pain is becoming one of the most common problems. According to current consumption and medical situation, it's generally recommended that pregnant women should wear the waist support belt to reduce pregnancy-related discomfort and get a life of high quality. The waist support belt, as the functional clothing, can be worn in everyday life. Then pregnant women can alleviate waist pain and support pregnant life with great convenience and comfort experience. It's significant to improve the product design and evaluation by force analysis. Analyzing the causes of the pregnancy-related waist pain by the theory of force can help designers and users have a clearer understanding of the function of the waist support belt.

The waist support belt is becoming more and more important for the pregnant women to relive pain. At present, some studies on the waist support belt and pregnancy-related waist pain are as follows both home and abroad. In term of survey, $10 \%-25 \%$ of women have pregnancy-related

${ }^{\star}$ Project supported by Shannxi Province's Research Center of Apparel Engineering and Technology for research funding support.

* Corresponding author.

Email address: yingba2006@163.com; 1789424568@qq.com (Bo-An Ying). 
waist pain, which is usually the first symptom for the most pregnant women during pregnancy $[1,2]$. The risk of pain for women who had lumbar pain maybe increases by two times [3]. Ya-zhen Pan researches on the situation in China, which has found that the prevalence of low back pain is $72.7 \%, 71.7 \%$ is reported by Wang and $68.5 \%$ is reported by Mogren, which all illustrate the incidence of pain is high [4-6]. The symptoms of pain often interfere with work, daily activities and sleep [7], and severe pain may need crutches, wheelchairs, or even completely bedridden $[8,9]$. According to a Swedish study, the cost including the treatment for pregnant waist pain and the maternity leave, is estimated to be 25,500 million dollars every year [10], but the pain cannot be completely cured, and may affect the future life.

Researchers have studied the causes of the waist support belt and pregnant waist pain. Chengxian Song and others introduce the causes and treatments of pregnancy-related waist pain during pregnancy [11]. Zi-qing Liu, Chao-yang Duan and others believe that uterus grows, the body weight of women and the lumbar angle increases, center of gravity moves forward, the focus on axial load of the lumbar metastases, intervertebral disc is compressed, lumbar back muscles are passive compensatory and in a state of continuous tension and fatigue, and body strength is imbalance before and after, so which cause pregnancy-related waist pain during pregnancy[12]. Foreign scholars have done a lot of researches on the waist pain of pregnant women, which is mainly about the causes of the waist pain and the measures to relieve the waist pain of pregnant women. Ritchie, J. R., Borg-Stein, J. and et al have shown that the lumbar lordosis increases due to excessive protruding during pregnancy, which causes pregnancy-related waist pain $[13,14]$. And the increased weight mainly concentrates on baby, and the center of gravity turns to $2 / 3$ of the front abdomen, and the center of weight leads to a downward trend. In order to restore the center of gravity, the pregnant women involuntarily arch their upper body and low extremities. Excessive protruding can affect the load distribution of the spine and result in abnormal mechanical stress, so muscle and lumbar ligament are strain, and what can result in the waist pain $[15,16]$. Fast A has discovered adjuvant therapy such as exercise, adjuvant therapy and the waist support belt can slow down waist pain of pregnant women [17]. Damen, L. and Spoor, C. W. et al find that waist support belts provide a stable external force to the spine and abdominal structure of pregnant women to relive the pain $[18,19]$. The functionality of waist support belt has not been verified by peer review or clinical trials. A small number of studies show the waist support belt cannot relive the waist pain.

The main works are including as following in this paper. Studying the cause of pregnancyrelated waist pain during pregnancy by force analysis is basic. Analyzing the function of waist support belt by force analysis, when pregnant women only wear the waist support belt, can determine whether help pregnant woman relieve the pain. When pregnant women wear waist support belt, testing pressure can judge whether the force analysis is reasonable. The function of the waist support belt is explained by the method of force analysis, and the evaluation method is provided in this paper.

\section{The Factors of Waist Pain in Pregnant Woman}

In the paper, the increased weight is assumed to be only on the abdomen during pregnancy, so the force analysis of pregnant is only on the upper part. At the same time, it is assumed that the weight of pregnant woman will not changed after the baby is born.

The factors of pregnancy-related waist pain are considered as the force acting on the waist 
muscles, the gravity of pregnant, the force acting on the spine. Pregnant woman's vertebral point is considered as the action point, then force analysis can be carried out. The condition of the force balance is that the external force is zero, which is the basic of analysis.

\subsection{The Force Analysis Before Pregnancy}

The forces of the muscles and the spine are calculated by the equation in the static equilibrium. At the time, there is no external force on the woman. Because of the symmetry, the force of the woman body in the $\mathrm{Z}$ direction is not considered in the analysis. The force analysis before pregnancy is analyzed as Figure 1. Figure 1 shows the schematic diagram of force analysis chart for one woman who isn't pregnant. According to the mechanical equilibrium condition, the force balance between the direction and the size meets the following equation.

$$
\begin{aligned}
& F_{\mathrm{GM}} \cdot a+F_{\mathrm{M}} \cdot c=0 \\
& F_{\mathrm{M}}+F_{\mathrm{T}}+F_{\mathrm{GM}}=0
\end{aligned}
$$

In Formula 1 and Formula 2, $F_{\mathrm{GM}}$ represents the weight of the woman before pregnancy. $F_{\mathrm{M}}$ represents the force acting on the lumbar muscles. $F_{\mathrm{T}}$ represents the force acting on the spine to support the gravity of human body. The a and c represent the arm of $F_{\mathrm{GM}}$ and $F_{\mathrm{M}}$ to the action point.

\subsection{Additional Force after Pregnancy}

There are some significant changes of maternal body after pregnancy. The most changes are fetus grows and pregnant belly shapes. To calculate the additional flexion moments in different trimesters $\left(T_{i}\right)$, the centre of mass $\left(B_{i}\right)$ of the expectant mother was assumed to lie halfway along the distance of the sagittal abdominal depth anterior to the spine centre which is shown in Figure 2. The additional torque $\left(M_{i}\right)$ imposed on the spine was calculated by multiplying the body weight gain $\left(F_{\mathrm{GFi}}\right)$ by the estimated centre of mass $\left(B_{i}\right)$. Thus, the equation for determining the additional flexion moments is as shown below:

$$
M_{i}=F_{\mathrm{GFi}} \times B_{i}
$$

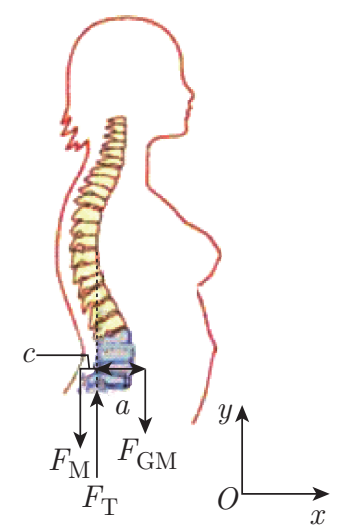

Fig. 1: The force analysis before pregnancy

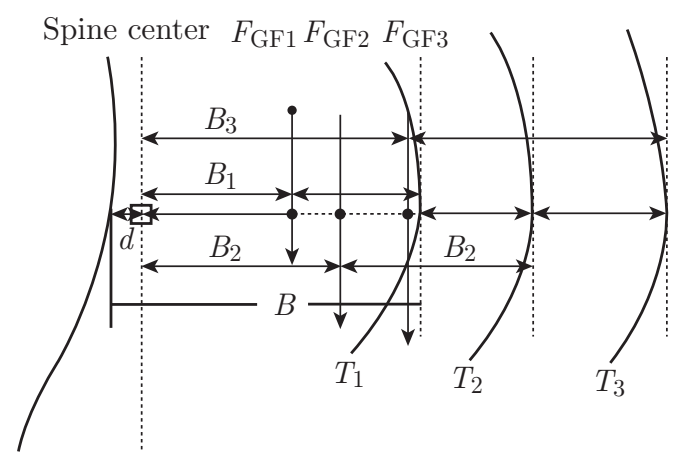

Fig. 2: Additional force after pregnancy 
With the growth of fetus, $F_{\mathrm{Gi}}$ and $B_{i}$ are constantly increasing, and the additional torque $\left(M_{i}\right)$ is increasing. And the distance between the back and the center of the spine is assumed to be 5 $\mathrm{cm}$, and it does not change.

\subsection{The Force Analysis for 9 Months Pregnant Woman}

When the growth of fetus is 9 months, the weight of the mother hasn't changed during pregnancy. The force analysis of the pregnant woman is shown in Figure 3. The force equilibrium state satisfies the following equation.

$$
\begin{aligned}
& F_{\mathrm{GM}} \cdot a+F_{\mathrm{GF}} \cdot b+F_{\mathrm{M}} \cdot c=0 \\
& F_{\mathrm{M}}+F_{\mathrm{T}}+F_{\mathrm{GF}}+F_{\mathrm{GM}}=0
\end{aligned}
$$

$F_{\mathrm{GF}}$ represents the weight of the fetus, and b represents the arm of the $F_{\mathrm{GF}}$ to the action point.

Force of $\mathrm{X}$ direction, waist muscle meets the Formula 3. From Figure 3, it can be seen that at this time the force of woman's waist obviously increases. Comparing with the Formula 1, there are obvious the fetal weight $\left(F_{\mathrm{GF}}\right)$ increases and the arm $(\mathrm{b})$ increases. However the c doesn't change significantly, so the force of waist muscle $\left(F_{\mathrm{M}}\right)$ increases. To offset the instability of body and increased weight, meanwhile t the force of waist muscles increases. Due to demand of fetus' growth, elastic relaxation and intrinsic stability of muscles decreases. The waist muscles for a long time are in a state of fatigue in theory.

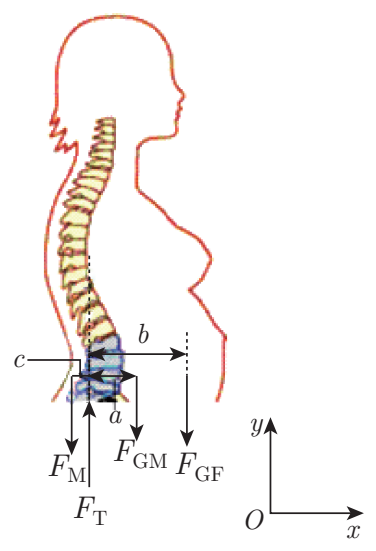

Fig. 3: The force analysis after pregnancy

Force of Y direction satisfies the following Formula 4. During the whole growth process, the force of fetus and waist muscles is increasing, the resultant force of lumbar increases.

According to the force analysis, the probability of waist pain is high.

\section{Force Analysis of Waist Support Belt}

It's easy to clear the function, through the force analysis of waist support belt. And waist support belt can relieve pregnancy-related pain and adverse effects of woman's normal life after birth of fetus. Avoiding waist muscle injury and fatigue can reduce the likelihood of pain. The force analysis of waist support belt is important on the basis of the analysis of the above. 


\subsection{Structural Analysis of Waist Support Belt}

When the pregnant woman wears waist support belt, the amount of relaxation between the two is negative. It proves there must has a certain pressure between woman and belt. When pregnant woman wears waist support belt, the waist support belt is closed by stretching. Different waist support belts support pregnant woman the different force. The factors affecting the force include the fabric elastic properties, fabric organization, the material properties, structure of steel bone and etc. As following, there are three structures of waist support belt used to analyze. The wearing states of pregnant woman and waist support belt are as shown in Figures 4-6.

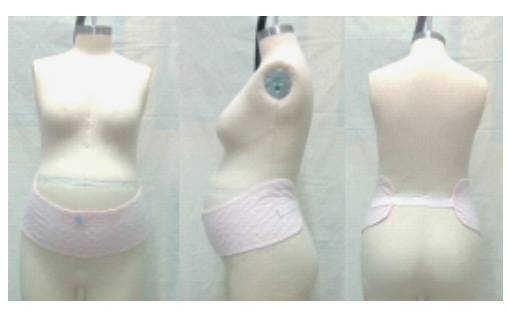

Fig. 4: Structure A of waist support belt

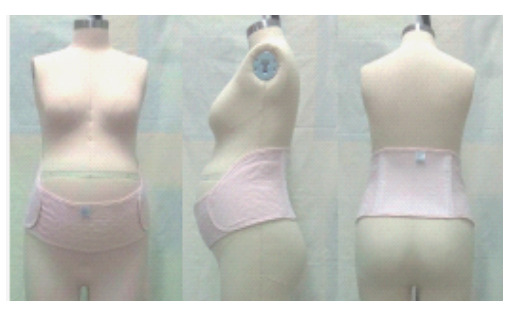

Fig. 5: Structure B of waist support belt

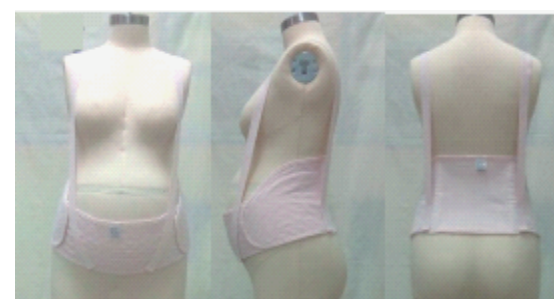

Fig. 6: Structure C of waist support belt

The three different parts constitutes of completed waist support belt. Each part is superimposed on the last part. The structure A is the first part. It is made of a certain elastic fabric and covers the surface of the human body. The certain binding force on the pregnant woman is supported by surrounding the pregnant woman's abdominal. But the support force is very limited in the waist and abdominal. The material properties of structure B of waist support belt is smaller elastic. It has the structure of steel bones on the back. The stronger force in the waist is supported. The force distribution looks like more reasonable. The structure $\mathrm{C}$ is a shoulder strap with less elastic properties. It is shaped long square. The structure $\mathrm{A}$ and $\mathrm{B}$, and $\mathrm{A}, \mathrm{B}$ and $\mathrm{C}$ can be integrated into a whole. The wearing state of waist support belt is right-and-left symmetrical basically, so the direction force of $\mathrm{z}$ is under no consideration.

\subsection{Force Analysis of the Waist Support Belt}

The fetal weight is supported by waist support belt. The waist support belt is helpful to reduce the force, so it have a supporting effect on pregnant woman. The waist support belt's force analysis is shown in Figure 7, in which the function of waist support belt is analyzed. As shown in the picture, it's important to satisfy force balance for the pregnant woman. The force of the waist belt satisfies the following formula on the pregnant woman.

$$
\begin{aligned}
& F_{\mathrm{M}} \cdot c+F_{\mathrm{GM}} \cdot a+\left(F_{\mathrm{GF}}+F_{1}\right) \cdot b+F_{\mathrm{B}} \cdot c=0 \\
& F_{\mathrm{M}}+F_{\mathrm{T}}+F_{\mathrm{GF}}+F_{\mathrm{GM}}+F_{1}+F_{\mathrm{B}}=0
\end{aligned}
$$

$F_{1}$ represents the a component of force in direction of $y$, the waist support belt acts on the abdominal of the pregnant woman, and $F_{\mathrm{B}}$ represents the force of the back force of the pregnant woman in direction of y. Compared with the above Formula 3 and Formula 4, the waist support belt has a certain force on the back part of the pregnant woman, and can reduce the weight of pregnant woman, which illustrates the waist support belt can relieve a little waist pain. 
The structure B has two steel bones on the back waist, which can support a certain force. The bones act the back waist, and can block the transfer of the large force. So waist of pregnant woman isn't affected by force, when women wearing waist support belt B. Meanwhile the waist support belt contacts with A by a fastening area. Comparing to structure A, the waist support belt of $\mathrm{B}$ has a greater tension on the waist and abdomen of pregnant woman. The force analysis of waist support belt is shown in Figure 8, showing that the force of the waist satisfies the following formula:

$$
\begin{aligned}
& F_{\mathrm{M}} \cdot c+F_{\mathrm{GM}} \cdot a+\left(F_{\mathrm{GF}}+F_{1}\right) \cdot b+F_{\mathrm{B}} \cdot c+2 F_{2} \cdot d=0 \\
& F_{\mathrm{M}}+F_{\mathrm{T}}+F_{\mathrm{GF}}+F_{\mathrm{GM}}+F_{1}+F_{\mathrm{B}}+2 F_{2}=0
\end{aligned}
$$

Among them, $F_{2}$ represents the supporting force is the part of the force bearing abdomen of the pregnant woman on the $\mathrm{Y}$ axis, and d represents the distance between $F_{2}$ and the point of the spine. Compared with Formula 5 and Formula 6, at the time the waist side of pregnant woman is significantly affected by the larger force $F_{2}$, and the effect of abdominal lifting is obvious. The waist support belt can relieve the waist pain of pregnant woman, and the effect of $B$ is larger than A.

The structure $\mathrm{C}$ is the shoulder strap. When the pregnant wears the structure $\mathrm{C}$, the wearing effect is shown in Figure 6. The force analysis of structure $\mathrm{C}$ is shown in Figure 9. At this time, By the force balance of waist, the following formula is obtained. At the time, the force will be shifted from the waist and abdomen to the shoulder.

$$
\begin{aligned}
& \left(F_{M}+2 F_{4}+F_{B}\right) \cdot c+F_{G M} \cdot a+\left(F_{G F}+F_{1}\right) \cdot b+2 F_{2} \cdot d+2 F_{3} \cdot e=0 \\
& F_{M}+F_{T}+F_{G F}+F_{G M}+F_{1}+F_{B}+2 F_{2}+2 F_{3}+2 F_{4}=0
\end{aligned}
$$

$F_{3}$ represents the pulling force of the shoulder strap on the abdomen of the pregnant woman, $F_{4}$ represents the pulling force of the shoulder strap on the back waist, and e is the distance between the $F_{3}$ and the point of the spine. The force of shoulder is large, and the shoulder strap can transfer the force of waist. Compared with Formula 7 and Formula 8, the force of pregnant woman's waist is smaller than before. The concentrated force is transferred to the shoulder, and

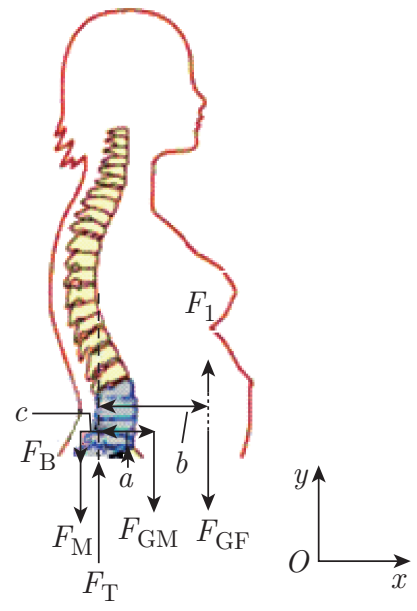

Fig. 7: The force analysis of structure A

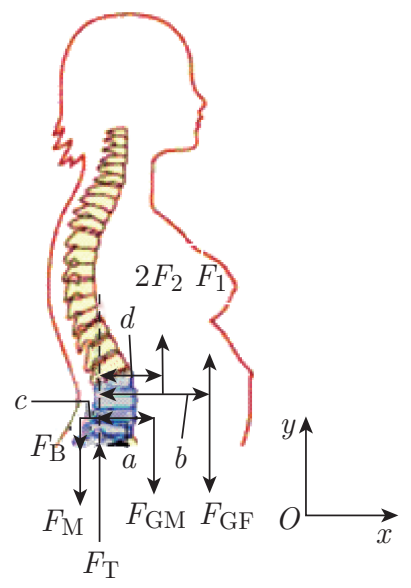

Fig. 8: The force analysis of structure B

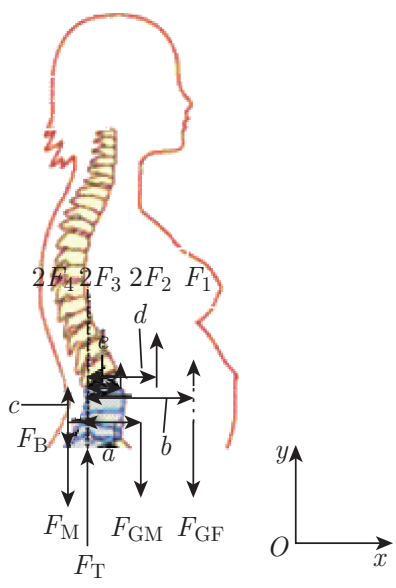

Fig. 9: The force analysis of structure $\mathrm{C}$ 
the shoulders of the human body can bear larger pressure, so that it can protect the waist of pregnant woman.

By analyzing the waist support belt, function of belt is explained clearly. In theory, pregnant woman wearing the waist support belt can indeed reduce the pain. So waist support belt is useful and important for woman during pregnancy.

\section{Pressure Test Experiment on Waist Support Belt}

\subsection{Experimental Conditions for Pressure Testing}

This pressure test uses the airbag pressure tester as shown in Figure 10. When the pressure is generated, the gas inside the balloon changes and is converted to electrical signal. The amplifier displays the signal in the digital display meter, and the pressure value is recorded in the software. The pressure test is important to verify the force analysis.

The experimental environment must be in a quiet constant temperature test room. According to the above force analysis and characteristics of waist support belt, the pressure test chooses marker points. The marker points can reflect changes of the force. The number of marker points is nine, which is as shown in Figure 11. Point 1 is located in the abdomen at the most convex below. Point 4 lies in fasteners of part $\mathrm{B}$, point 3 lies in fasteners of part $\mathrm{C}$, point 5 and point 6 are on the same horizontal line, point 6 is under the fasteners of back, point 7 and point 8 are both sides of part B, and point 9 lies in the shoulder.

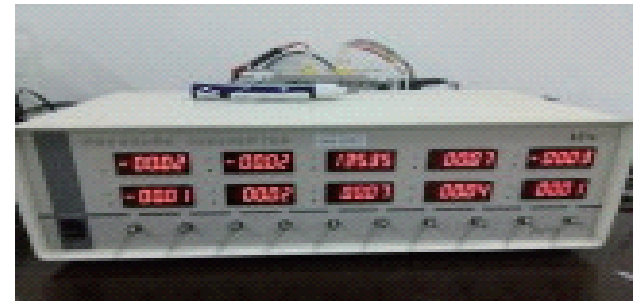

Fig. 10: The airbag pressure tester
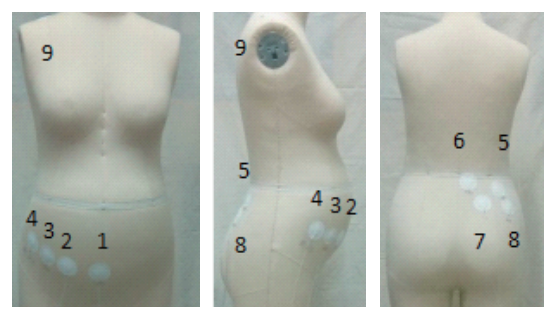

Fig. 11: The marker points

The three structures of pressure test are same as the force analysis. Every structure of waist support belt are measured five times. After the measurement every time, belts are placed a period of time to restore the original. By testing the pressure, the changes of different waist support belts are obvious. The pressure values are as shown in Table 1, 2 and 3.

Table 1: The pressure values of structure A Unit: Kpa

\begin{tabular}{lcccccc}
\hline & Point 1 & Point 2 & Point 3 & Point 4 & Point 5 & Point 6 \\
\hline Test 1 & 1.12 & 2.29 & 1.29 & 1.85 & 1.07 & 2.17 \\
Test 2 & 1.23 & 2.27 & 1.54 & 1.75 & 0.85 & 1.77 \\
Test 3 & 0.89 & 1.89 & 1.53 & 1.76 & 0.89 & 1.71 \\
Test 4 & 1.04 & 2.05 & 1.83 & 1.88 & 1.07 & 1.85 \\
Test 5 & 1.07 & 2.16 & 1.61 & 1.76 & 0.71 & 1.39 \\
\hline
\end{tabular}


Table 2: The pressure values of structure B Unit: Kpa

\begin{tabular}{lcccccccc}
\hline & Point 1 & Point 2 & Point 3 & Point 4 & Point 5 & Point 6 & Point 7 & Point 8 \\
\hline Test 1 & 1.04 & 2.46 & 1.57 & 2.33 & 1.03 & 2.34 & 1.06 & 2.16 \\
Test 2 & 0.86 & 2.17 & 1.58 & 1.95 & 1.07 & 1.53 & 1.25 & 2.46 \\
Test 3 & 0.94 & 2.11 & 1.80 & 2.12 & 0.90 & 1.82 & 0.86 & 2.36 \\
Test 4 & 1.00 & 2.43 & 1.83 & 2.19 & 1.17 & 2.10 & 1.06 & 2.35 \\
Test 5 & 0.96 & 2.28 & 1.70 & 1.82 & 0.62 & 1.55 & 1.01 & 2.01 \\
\hline
\end{tabular}

Table 3: The pressure values of structure C Unit: Kpa

\begin{tabular}{lccccccccc}
\hline & Point 1 & Point 2 & Point 3 & Point 4 & Point 5 & Point 6 & Point 7 & Point 8 & Point 9 \\
\hline Test 1 & 0.96 & 2.29 & 1.97 & 2.11 & 1.02 & 2.28 & 1.01 & 2.41 & 2.71 \\
Test 2 & 0.81 & 2.10 & 2.04 & 1.83 & 1.18 & 1.69 & 1.32 & 2.56 & 3.27 \\
Test 3 & 0.98 & 2.08 & 2.13 & 2.06 & 0.86 & 1.82 & 0.78 & 2.48 & 2.79 \\
Test 4 & 0.91 & 2.28 & 2.21 & 2.14 & 1.09 & 2.16 & 1.18 & 2.39 & 2.98 \\
Test 5 & 0.91 & 2.19 & 1.98 & 1.78 & 0.68 & 1.64 & 0.98 & 2.09 & 3.02 \\
\hline
\end{tabular}

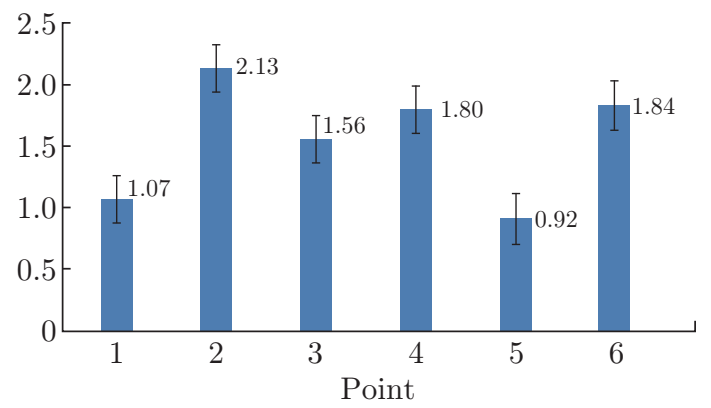

Fig. 12: The pressure values of structure A

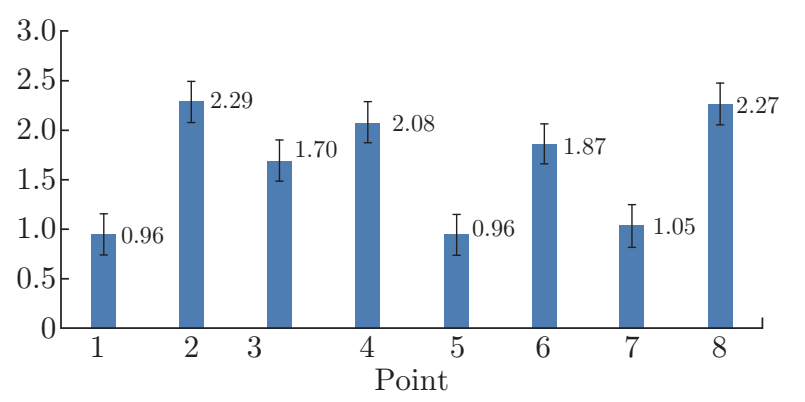

Fig. 13: The pressure values of structure B

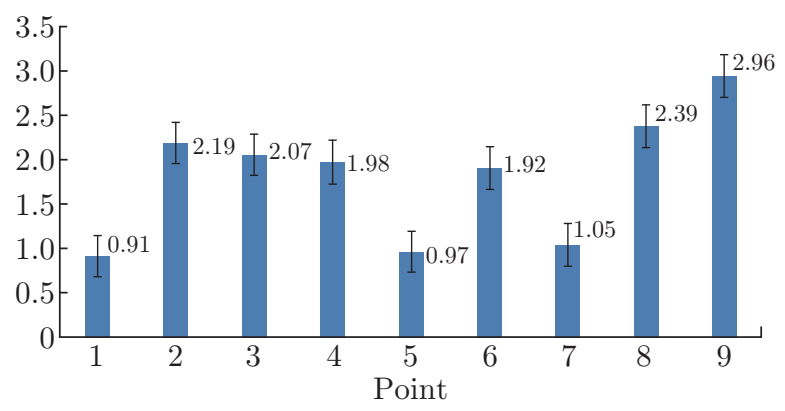

Fig. 14: The pressure values of structure $\mathrm{C}$

\subsection{Result Analysis and Discussion-Plot the Data and Add Statistical Analysis Results}

By testing the pressure, the changes of different waist support belts are obvious. The pressure values are as shown in Fig. 12-14. Difference data explain the steel bone can decrease force, comparing the Point 7 and Point 8. It is found that value of point 4 has distinct increase, 
when wearing structure B. By comparing data, value increases except for point 1 . It shows that structure B of the waist support belt has stronger binding force. The pressure value of the fastening increases obviously, but the pressure value at the rear waist is not obvious.

The pressure values of different structures are shown in Fig. 15. Compared with the B, there has a slight decrease in $\mathrm{C}$. The decrease indicates $\mathrm{C}$ has a significant effect on the abdominal. When the maximum pressure on the shoulder, it makes the force more uniform. The waist support belt can better relieve the waist force. Then belt can reduce the pain of pregnant woman.Analyzing values, according to the force analysis and structures, can verify the force analysis. And force analysis is reasonable.

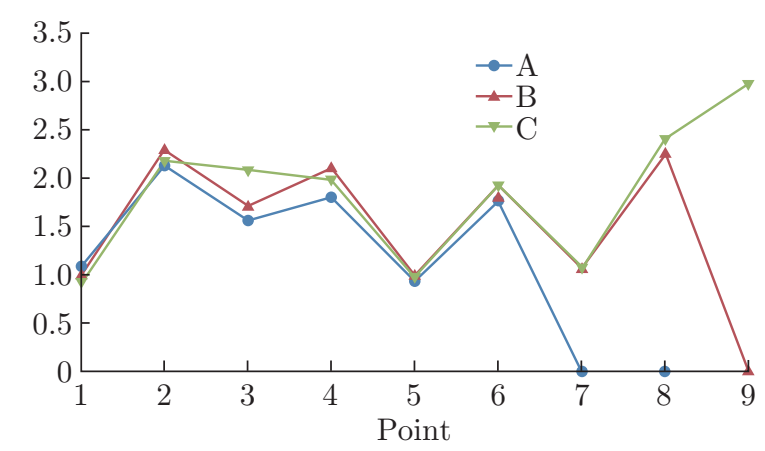

Fig. 15: The pressure values of different structures

Then theory and experiment all illustrate support belt can help the pregnant women to relieve the pain well. Theoretical analysis and experimental results are agreed.

\section{Conclusion}

The main achievements and conclusions of this research are as follows:

1) The support belt is used to relieve the pain during the pregnancy, as a common pregnant woman's clothing. In this paper, through force analysis method and the angle of mechanical balance, the cause of pregnant woman's waist pain and the function of support waist belt are analyzed using the equation.

2) The pressure test is effective to verify the rationality of the waist support belt relieving the pain of pregnant woman from the mechanical angle. Force analysis provides an effective method for the design and evaluation of the waist support belt.

3) Though force analysis and pressure test explain belts help pregnant women to relieve waist pain effectively, the function of belt on pregnant is effective. There has not pain tests for pregnant women to explain how much the belt can relieve pain.

\section{Acknowledge}

The work is supported by research funding, Shannxi Province's Research Center of Apparel Engineering and Technology. 


\section{References}

[1] Biering-Sorensen F. A prospective study of low back pain in a general population. Occurrence, recurrence and aetiology [J]. Scandivian: J REHABIL MED: 1983, 15: 71-79.

[2] Svensson HO, Andersson GB, Hagstad A, Jansson P O. The relationship of low-back pain to pregnancy and gynecologic factors [J]. SPINE J: 1990, 15: 371-375.

[3] Ostgaard HC, Andersson GB. Previous back pain and risk of developing back pain in a future pregnancy [J]. SPINE J: 1991, 16: 432-436.

[4] Wang SM, Dezinno P, Maranets I, et al. Low Back Pain during Pregnancy: Prevalence, Risk Factors, and Outcomes [J]. OBSTET GYNECOL: 2004, 104(1): 65-70.

[5] Mogren IM, Pohjanen AI. Low Back Pain and Pelvic Painduring Pregnancy: Prevalence and Risk Factors [J]. SPINE J: 2005, 30(8): 983-991.

[6] Ya-Zhen Pan, Characteristic of pregnancy-related pelvic girdle pain in women during late stage of pregnancy and its influence on daily life [J]. AM J NURS: 2012, 2(19): 51-53.

[7] Jensen DV, Wormslev M, Minck H, Johansen S, Larsen EC, Wilken-Jensen C, et al. Pregnancy associated pelvic pain. II: Symptoms and clinical findings [J]. Ugeskrift For Laeger: 2000, 162: 4813-4817.

[8] Van Zwienen CM, Van den Bosch EW, Snijders CJ, Van Vugt AB. Triple pelvic ring fixation in patients with severe pregnancy-related low back and pelvic pain [J]. SPINE J: 2004, 29: 478-484.

[9] Mirza FG, Devine PC, Gaddipati S. Trauma in pregnancy: A systematic approach [J]. Am J Perinatol: 2010, 27: 579-586.

[10] Noren L, Ostgaard S, Nielsen TF, Ostgaard HC. Reduction of sick leave for lumbar back and posterior pelvic pain in pregnancy [J]. SPINE J: 1997, 22: 2157-2160.

[11] Chen-Xian Song, Run-Mei Wang, Tai-Liang Li, Juan Liu. Epidemiological characteristics and therapeutic progress of pregnancy-related low back pain [J]. CGP: 2017, 15(04): 659-662.

[12] Zi-Qing Liu, Chao-Yang Duan, Meng-Yun Chen, Lin-Yi Fu and et al. Biomechanical characteristics of pregnancy-related low back pain and pelvic pain [J]. CGP: 2017, 20(S2): 197-200.

[13] Ritchie JR. Orthopedic considerations during pregnancy [J]. CLIN OBSTET GYNECOL: 2003, 46: 456-466.

[14] Borg-Stein J, Dugan S A, Gruber J. Musculoskeletal aspects of pregnancy [J]. AM J PHYS MED REHAB: 2005, 84: 180-192.

[15] MacEvilly M, Buggy D. Back pain and pregnancy: a review [J]. PAIN: 1996, 64: 405-414.

[16] Monaco JE. Orthopedic considerations in pregnancy [J]. Primary Care Update for Ob/gynecology: 1996, 3: 197-200.

[17] Fast A. Low back pain during pregnancy. In A. J. Cole \& S. A. Herring (Eds.), Low back pain handbook: A guide for the practicing clinician [D]. Philadelphia: Hanley \& Belfus Inc: 2003, 405-412.

[18] Damen L, Spoor CW, Snijders CJ, Stam HJ. Does a pelvic belt influence sacroiliac joint laxity? [J]. CLIN BIOMECH: 2002, 17: 495-498.

[19] Mens JM, Damen L, Snijders CJ, Stam HJ. The mechanical effect of a pelvic belt in patients with pregnancy-related pelvic pain [J]. CLIN BIOMECH: 2006, 21: 122-127. 